Drake argues, central to Galileo's astronomical system, though it was pushed somewhat into the background by papal pressure before the publication of the Dialogo of 1632 .

Drake does not here defend the scientific adequacy of Galileo's theory of tides, nor the adequacy of his concept of inertia, nor one or two other positions which have seemed idiosyncratic to other scholars. His 'reconstructions' are balanced, clever, and well-documented. As in other books by him, 'the philosophers' come in for a good many hard knocks: 'There is a vast difference between confidence grounded in repeated observations and careful thought, and the confidence of philosophers in metaphysical principles that transcend all experience of mere astronomers', remarks Salviati. Drake (and other scholars) have successfully vindicated their claim for the historical veracity of Galileo's experimental approach to mechanics; here he extends the lesson to the successful matching of mathematical formulations with carefully compiled observations on Galileo's part. There is a great deal here which is new and really important. Drake stands with those who argue that the historical process of the separation of natural science from philosophy, metaphysics and, indeed, magic was just as important as the fact of the continuity of elements derived from these sources in natural science. For it was by separation that the special character of science was established.

Drake has tried to give a new and more lively form to the often pedantic literature of the history of science, and so to arouse a new curiosity. Whether or not he succeeds in that aim, his imaginary conversations, like those of Galileo himself, contain new truths vividly argued.

A. Rupert Hall is Emeritus Professor of the History of Science, Imperial College, University of London.

\section{Stepping through the Universe}

\section{A.T. Winfree}

Powers of Ten: About the Relative Size of Things in the Universe.

By Philip Morrison and Phylis Morrison and the Office of Charles and

Ray Eames.

W.H. Freeman: 1982. Pp.150.

$\$ 29.95$, £11.95.

TWELVE months ago, the editors of Scientific American launched the Scientific American Library as a book club, with books appearing at two month intervals, each being reissued as a trade book 12 months later at a higher price. Intended for a popular audience, the series is pitched at a level somewhere between the monthly magazine articles (which I personally consider demanding reading) and Time/Life picture books. Each is written by a scientist, many by Nobel Laureates, not by the editorial staff. Each presents a subject that cuts across diverse specialized disciplines. The first six issues have already been produced.

Powers of Ten is the premier issue and the first available to the general public. It is by far the least technical of the books produced up to now, and demonstrates the publishers' commitment to readability and quality graphics, in $22 \mathrm{~cm}$ square format with colour pictures on almost every page. The theme is familiar and not subtle: phenomena in the natural world vary over something like $\mathbf{4 2}$ orders of magnitude in linear dimensions (ignoring volume, time scales, etc.), and differ in character according to scale. Many books have presented this theme to diverse audiences. So in this case everything depends on targeting the right audience and on skill in presentation. The Morrisons' art work is superb, as one might have expected from their track record, and from the immediate antecedent of the book: the wonderfully succesful ten minute motion picture of 1968 and 1977 (improved) by the same name.

The core of Powers of Ten is a sequence of 42 colour plates, the first suggesting most of the Universe. In the next plate $\left(10^{24}\right.$ metres) some galactic clusters become big enough to see, as a giant step forward brings us ten times closer to the nucleus of a certain carbon atom in the very centre of that cosmic field of view . . . and so on through 42 steps. By the 25 th step we have converged on a couple lying on a picnic blanket and we continue, ending after 17 more steps in a subnuclear blur that might represent quarks.

Facing the colour plate at each step is a page of text and smaller pictures illustrating some of the phenomena characteristic of that size scale. For example facing the 10 metre to $10^{-6}$ metre pictures, most of the illustrations are biological. On every scale, the chosen examples are rich with surprising titbits of insight, presented from a unique perspective.

This core is only $60 \%$ of the book. The appendices are no less fascinating; in fact the one entitled "Rules for a Journey of Mind and Eye" might be the best place to start: it tells how the pictures were planned. My own taste is then to run backwards through the plates, starting with quarkblur. Other appendices gather some pertinent history of science; the 20 pages of "Sources and Notes" make particularly good reading.

A.T. Winfree is Professor of Biology at Purdue University, Indiana.
The Diversity of Green Plants

Third Edition

Peter Bell and Christopher Woodcock Contemporary Biology Series

A well-illustrated evolutionary account of the photosynthetic plants, from the algae to the flowering plants, paying particular attention to those plants prominent in current research. £9.95 paper 368 pages

\section{The Biology of Lichens}

\section{Third Edition}

Mason E. Hale

Contemporary Biology Series

A review of all aspects of lichenology.

This new edition has been rewritten, stressing ultrastructure studies and taking account of the tremendous progress in the study of lichen resynthesis and the physiology of symbiosis.

£8.95 paper 200 pages

\section{The Physiology of Flowering Plants}

Third Edition

H.E. Street and Helgi Opik

Contemporary Biology Series

This book treats plant physiology from the viewpoint of the whole plant or organ, with particular emphasis on growth and development. New additions to this edition include a treatment of the general physiology of photosynthesis, and an expansion of the topic of stress resistance.

£8.50 approx paper 296 pages fanuary

\section{Immunity to Parasites}

How animals control parasite infections

\section{Derek Wakelin}

The book concentrates on selected hostparasite systems, all of clinical or economic significance, which illustrate particular aspects of parasite adaptation and of host response, and in which immunologically oriented research has made significant progress.

£9.50 approx paper 192 pages March

\section{The Biology of the Coccidia}

Edited by Peter L. Long

This is the thoroughly revised and updated version of The Coccidia edited by the late Dr Hammond and Dr Long. It includes new chapters on chemotherapy and new details of life cycles of several species of Sarcocystis and Toxoplasma.

... this has turned out to be a significant volume which in the present climate of scientific work may have been produced just in time.' British Veterinary fournal $£ 45$ boards 512 pages

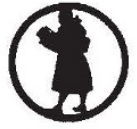

Edward Arnold

41 Bedford Square London WC1B 3DQ 